\title{
Climate Change: Evidence of Human Causes and Arguments for Emissions Reduction
} Seth D. Baum, ${ }^{1,2}$ Jacob D. Haqq-Misra, ${ }^{3}$ and Chris Karmosky ${ }^{1}$

1. Department of Geography, Pennsylvania State University, http://sethbaum.com

2. Center for Research on Environmental Decisions, Columbia University

3. Department of Meteorology and Astrobiology Research Center, Pennsylvania State University

Science and Engineering Ethics, 18(2):393-410.

Received: 2 April 2009; Accepted: 3 February 2011. This file version: 6 August 2012.

\begin{abstract}
In a recent editorial, Raymond Spier expresses skepticism over claims that climate change is driven by human actions and that humanity should act to avoid climate change. This paper responds to this skepticism as part of a broader review of the science and ethics of climate change. While much remains uncertain about the climate, research indicates that observed temperature increases are human-driven. Although opinions vary regarding what should be done, prominent arguments against action are based on dubious factual and ethical positions. Thus, the skepticisms in the recent editorial are unwarranted. This does not diminish the general merits of skeptical intellectual inquiry.
\end{abstract}

Keywords: Climate change, skepticism, transdisciplinarity, uncertainty, economics

\section{Introduction}

Carl Sagan once said, "extraordinary claims require extraordinary evidence". The claim that human actions may be altering the global climate system via emissions of greenhouse gases is quite extraordinary. However, a growing chorus of climate science researchers is making precisely this claim (Solomon et al. 2007). Meanwhile, many academics (e.g. Nordhaus 2008; Stern 2007) and public leaders (e.g. Gore 2006) make the ethical claim that society should be doing more to reduce greenhouse gas emissions.

Spier (2008) expressed skepticism towards both of these claims. While we do not share his doubts, skepticism is a central element of scientific thought and is commendable because it leads to more accurate beliefs. Thus, we share the spirit in which the skepticism was expressed, though not the doubts themselves.

\section{Climate Research}

Before considering the details of the science and ethics of climate change, it is helpful to have some sense for the context in which this work is conducted. The climate system, like so many other large, complex systems, cannot be studied in a traditional laboratory research setting. One cannot conduct an experiment that raises greenhouse gases to a certain level, observe what happens, and then use the observations to inform climate change strategy. Such an experiment would involve customizing the entirety of civilization and would cause climatic changes that have major impacts on humans and ecosystems worldwide. These experiments are ethically unacceptable and physically impossible. Furthermore, many climate changes occur on a much 
longer time scale than one can observe in any realistic experiment, often on the order of centuries to millennia.

As climate scientist Stephen Schneider (2006) noted, climate change research is a post-normal science (c.f. Ravetz 1999), that is, the phenomena to be studied are complex, the stakes are high, and the available time for research is insufficient. Thus, waiting until it is clear how the climate system works before making decisions will probably be "too late". This point is driven home strongly in the recent report National Security and Climate Change, produced by the CNA Corporation and a decorated team of retired military leaders (Sullivan et al. 2007; see also Ascher 2004.)

Climate change research also does not fit neatly into conventional academic disciplinary divisions. The research is highly interdisciplinary, incorporating research from many disciplines, and transdisciplinary, transcending traditional disciplinary boundaries towards new forms of knowledge (Lawrence and Després 2004). The Intergovernmental Panel on Climate Change (IPCC) as well as journals such as Climatic Change welcome and receive contributions from virtually all academic perspectives that have relevant contributions to make. As the U.S. National Academies have argued, this integrative approach is vital to addressing problems like climate change (Committee on Facilitating Interdisciplinary Research 2004).

Moreover, because diverse researchers contribute to the study of climate change, one cannot easily define the climate change research community. Regardless of how the community is defined, it has been the focus of extensive inquiry. The most damning accusation is that the community has fabricated the climate change issue in order to attract more research funding. In the controversial film The Great Global Warming Swindle (Durkin 2007), Martin Durkin called climate change "a multibillion-dollar worldwide industry, created by fanatically anti-industrial environmentalists, supported by scientists peddling scare stories to chase funding, and propped up by compliant politicians and the media" (cited in Washington Times 2007).

To the best of our knowledge, this charge is unequivocally false. Climate change researchers are generally similar to other researchers: interested in advancing the frontiers of human knowledge while maintaining concern for the welfare of civilization and the planet. If anything, researchers may not be politically engaged enough. As Schneider wrote, "most scientists are woefully unaware of the social context of the implications of their work and are too naïve to be politically conspiratorial" (Schneider 2001, p. 342). Meanwhile, although public awareness of climate change is rising, it does not rank as a top issue in many countries, for example, the U.S. (Leiserowitz 2006). Thus, a case can be made for climate researchers to be more active in public outreach, not to peddle false hysteria but to help set the record straight.

The rising awareness of climate change is due in part to the IPCC, which was recently awarded a share of the Nobel Peace prize "for their efforts to build up and disseminate greater knowledge about man-made climate change, and to lay the foundations for the measures that are needed to counteract such change" (Nobel Foundation 2007). The IPCC, a research organization under the World Meteorological Organization (part of the United Nations) and the United Nations Environment Programme, is charged with being "policy-relevant but not policy-prescriptive" (Pittock 2002, p.393). IPCC reports are essentially giant literature reviews, presenting the state of 
climate change research. The reports are particularly careful to present uncertainty regarding human understanding of the climate system (Moss and Schneider 2000), although some researchers have criticized the reports for focusing too much on the most likely scenarios at the expense of lower-probability catastrophic scenarios (Kerr 2007). Nonetheless, the IPCC reports are highly regarded among climate change researchers and remain authoritative statements of the state of the research. (For more on the IPCC, see Saundry and Vranes (2008), Shaw and Robinson (2004), or the IPCC website, http://www.ipcc.ch)

\section{Climate Science}

Earth's climate is a highly complex system, but some key aspects of it can be described in relatively simple terms. A good starting point for understanding Earth's climate is through the planet's basic radiative equilibrium, i.e. the equilibrium between radiation coming in from the sun and returning back to space. About $30 \%$ of incoming solar radiation is reflected back to space by clouds or by Earth's surface. The other $70 \%$ is mostly absorbed by the surface. This absorption warms the surface and in turn causes the surface to emit an equal amount of energy in the form of infrared radiation up toward space, in accordance with the concept of blackbody radiation.

However, the radiative equilibrium temperature for present-day Earth is almost twenty degrees below the freezing point of water. If the sun alone warmed our planet, then life as we know it would be impossible. Fortunately, the atmosphere provides another important source of energy. Certain atmospheric constituents known as greenhouse gases (such as water vapor, carbon dioxide, methane, and nitrous oxide) absorb infrared radiation from the surface and re-radiate in all directions, including downward, which provides additional surface warming. The crucial role of greenhouse gases in warming the Earth is elaborated in the simple climate model presented in the Appendix.

Anthropogenic (human-caused) greenhouse gas emissions serve to increase surface temperature. However, this fact alone is insufficient to attribute the warming observed over the last several decades to anthropogenic emissions. Other processes could be relevant. It is also important to consider the sources of greenhouse gas emissions (mainly the burning of fossil fuels) and the sinks for greenhouse gasses (mainly photosynthesis), as well as how these processes unfold over time. However, even after factoring in these processes, the observed warming cannot be reproduced without including anthropogenic greenhouse gas emissions as a factor.

Anthropogenic greenhouse gas emissions also appear to be driving further temperature increases and other climatic changes in the future. The exact nature of the changes is uncertain. One reason for this uncertainty is that the amount of total greenhouse gas that humanity will emit in the future is unknown. Another reason for this uncertainty is that the understanding of the climate system, though strong, remains imperfect.

Spier's Skepticisms

In his editorial, Spier questions four aspects of climate science: (1) an observed temperature decline between 1943 and 1975; (2) ice-core data which Spier interprets as evidence that changes 
in temperature cause changes in carbon dioxide $\left(\mathrm{CO}_{2}\right)$ in the atmosphere, instead of changes in $\mathrm{CO}_{2}$ in the atmosphere causing changes in temperature; (3) the role of cloud formation in global temperature; and (4) the role of cosmic rays in global temperature (Spier 2008).

\section{Observed Temperature Decline Between 1943 and 1975}

While it is true that global temperature records show a temperature decline from 1943 to $1975,{ }^{1}$ even while greenhouse gas concentrations were increasing, this temperature decline does not disprove the claim that broader temperature increases are driven primarily by greenhouse gas emissions. Instead, it highlights another contributor to global temperatures: sulfur emissions, which form sulfate aerosols in the atmosphere that reflect additional incoming solar radiation back to space (an increase in albedo) and thus cool Earth's surface. Sulfur emissions began with a rapid rise in industrialization following World War II and peaked around 1980 (Stern 2005). During this time greenhouse gas emissions grew more slowly than sulfur emissions, which led to net cooling while the sulfate aerosols dominated (Ramaswamy et al. 2001). When sulfate aerosols are included in climate models, this same temperature decline appears, along with the familiar longer-term warming trend (Harvey and Kaufmann 2002; Stott et al. 2006).

If past sulfur emissions caused lower temperatures, could the emission of more sulfate aerosols now offset temperature increases? It seems likely. Such large-scale intentional efforts to alter Earth's climate are known as geoengineering (Keith 2000). Other geoengineering techniques include dumping iron in oceans to stimulate photosynthetic phytoplankton (Martin 1990; Smetacek and Naqvi 2008) and placing large shields at the L1 Lagrange point between Earth and the sun (Early 1989; Seifritz 1989). While geoengineering is highly controversial (Morton 2007), it is increasingly receiving serious attention (Crutzen 2006; Schneider 2008), largely motivated by humanity's perceived failure to adequately reduce greenhouse gas emissions.

\section{Interpreting Ice Core Data}

Because there are few human-produced records of climate longer than 150 years, to learn about past climates, one must seek information from climate proxies. Some of the most informative climate proxies are ice cores on Greenland and Antarctica. The cores, up to two miles deep, provide information for periods of hundreds of thousands of years (Alley 2002).

Spier claims that ice core data presented by Petit et al. (1999) indicate that historic temperature increases preceded atmospheric $\mathrm{CO}_{2}$ increases, suggesting that temperature increases cause $\mathrm{CO}_{2}$ increases, instead of the other way around as would be expected under the view that $\mathrm{CO}_{2}$ increases are driving current global warming. We are unable to conclusively reproduce this assessment from our own analysis of the work of Petit et al. (1999). Ice core data show that $\mathrm{CO}_{2}$ and temperature have fluctuated in synch with each other as a result of Milankovitch cycles (variations in Earth's orbital patterns), demonstrating a correlation between the two but no causation. The causal role of $\mathrm{CO}_{2}$ as a greenhouse gas is derived from the well-understood physical properties of the $\mathrm{CO}_{2}$ molecule. There is also positive feedback in that increased

\footnotetext{
${ }^{1}$ The observed decline is shown in Figure 3.1 of the IPCC report (Solomon et al 2007) as a negative deviation from the 1961 to 1990 mean temperature, based on several data reconstructions (Brohan et al. 2006; Hansen et al. 2001; Lugina et al. 2005; Smith and Reynolds 2005).
} 
warming of the oceans can cause a decrease in the saturation concentration of $\mathrm{CO}_{2}$ in the ocean waters. As a result, $\mathrm{CO}_{2}$ is released into the atmosphere from warming oceans and can cause further atmospheric warming. $\mathrm{CO}_{2}$ concentrations thus can either lag or precede temperature increases. Even if it is demonstrated that in one situation atmospheric $\mathrm{CO}_{2}$ levels were driven by a temperature change, this does not exclude the possibility that $\mathrm{CO}_{2}$ concentrations may drive temperature changes in other situations.

\section{The Role of Cloud Formation}

Clouds do play an important role in surface air temperatures: water vapor is Earth's most prevalent greenhouse gas, so increased cloud cover will cause surface warming. However, clouds also reflect incoming solar radiation back into space, thereby cooling Earth's surface. In general, thick clouds, such as the cumulonimbus clouds found in thunderstorms, tend to have a net cooling effect on Earth's surface, whereas thin clouds, such as high cirrus clouds, have a net warming effect (Grenci and Nese 2006). Higher global temperatures will cause higher rates of evaporation, bringing more of both thick and thin clouds. Clouds thus constitute an important source of uncertainty in future temperature change.

\section{The Role of Cosmic Rays}

The amount of incoming radiation from both the sun and other cosmic ray sources is not constant over time. As Spier (2008) indicates, some researchers have claimed that these cosmic ray fluctuations are at least as dominant a driver of global temperature changes as greenhouse gas emissions, including via changes in cloud cover (Carslaw et al. 2002; Marsh and Svensmark $2000 \mathrm{a}, \mathrm{b})$. However, there is no apparent correspondence between the cosmic ray time series and global low-level cloud cover past 1994 (Kristjánsson et al. 2002, 2004; Sun and Bradley 2002). Likewise, the overall contribution of solar variability to global radiative forcing is small relative to anthropogenic contributions (Solomon et al. 2007).

\section{Key Remaining Uncertainties}

While there is now high confidence that ongoing temperature increases are driven by anthropogenic greenhouse gas emissions, there are nonetheless aspects of the climate system that remain imperfectly understood because, as noted above, the climate system is too large and complex to be studied in exhaustive detail. Some key remaining uncertainties in the understanding of the climate system have important consequences for the ethics of climate change.

\section{Climate sensitivity}

Climate sensitivity is defined as the average global temperature increase that would come from a doubling of atmospheric $\mathrm{CO}_{2}$ concentration. ${ }^{2}$ Average global temperature is not a perfect proxy for aggregate climate change: temperature changes are not uniform across Earth, and other

\footnotetext{
${ }^{2}$ Since pre-industrial times, atmospheric $\mathrm{CO}_{2}$ concentrations have increased from approximately from 280 to 380 parts per million and may get as high as 1000 parts per million by 2100, still rising thereafter (Solomon et al. 2007). Scenarios in which concentrations reach 1700 parts per million are considered in Archer (2005), and even this may not be an upper bound. Thus, total temperature increase may be several times the climate sensitivity.
} 
climatic changes such as changes in precipitation, severe weather events, and climate variability are also important. However, average global temperature is nonetheless often a reasonable approximation of aggregate climate change, which makes climate sensitivity a variable of great interest.

Climate sensitivity has been studied since the early days of climate change research (Arrhenius 1896). However, the exact magnitude of climate sensitivity remains unknown, due to uncertainty about positive and negative feedbacks in the climate system in which a response to warming could lead to additional warming or cooling. As noted above, perhaps the main uncertain feedback is in clouds. The basic physics of greenhouse gases indicates that, without these feedbacks, climate sensitivity would be an increase of approximately $1.2^{\circ} \mathrm{C}$. As a result of the cumulative effects of all of the planet's feedback systems, climate sensitivity is frequently estimated to be approximately $3^{\circ} \mathrm{C}$ but magnitudes as high as $6^{\circ} \mathrm{C}$ or even $10^{\circ} \mathrm{C}$ have not been ruled out (Knutti and Hegerl 2008). A high climate sensitivity could result in catastrophic outcomes.

\section{Ice melt and sea level rise}

Climate change causes melting of ice sheets, which in turn sends water into the oceans and causes sea level rise. The magnitude of this sea level rise remains uncertain. Earth currently features three major ice sheets: the Greenland Ice Sheet (GIS), the West Antarctic Ice Sheet (WAIS), and the East Antarctic Ice sheet (EAIS). (The WAIS and EAIS are separated by a major mountain chain running across Antarctica.) The EAIS is the largest of the three ice sheets, but is very stable and thus unlikely to melt within the next several centuries. By contrast, the WAIS and GIS are much less stable and are thus of more immediate concern. The instability of these ice sheets has been inferred from observations of recent geologic history (Conway et al. 1999; Overpeck et al. 2006) as well as calculations with computer models of ice sheet dynamics (Clark et al. 1999; Pollard and DeConto 2009). Satellite measurements also show that melting by both the GIS and WAIS has accelerated over the past decade, which has contributed to a steady rise in sea level (Rignot and Kanagaratnam 2006; Shepherd and Wingham 2007). The ice sheets are projected to shrink even further as temperatures continue to rise (Solomon et al. 2007). However, projections for future ice melt remain uncertain. The projections are based primarily on coupled atmosphere-ice sheet models. Current models are not successful at approximating all aspects of the atmosphere-ice system. One important source of uncertainty is the increase in ice stream velocity that comes from lubrication from "surface melt": ice on the surface of ice sheets that melts and falls to the bottom of the sheets (Zwally et al. 2002). While this lubrication is certain to cause a net rise in sea level, the amount of the rise is unknown.

In general, what is of importance is not only how much the sea level rises, but also how fast this rise occurs, because a rapid rise gives humans and ecosystems less time to adapt to the change. There is presently much concern that an abrupt ice sheet collapse could cause a rapid sea level rise. The WAIS is particularly prone to abrupt collapse because it rests on ground that lies below sea level. If the surrounding oceans warm enough, then WAIS could rapidly disintegrate. Meanwhile, the Antarctic Peninsula, home to the northernmost fringes of WAIS, is undergoing perhaps the largest increase in temperature of any location on the planet (King et al., 2002; Turner et al., 2005), and there are already some warning signs that a WAIS collapse could be in 
progress. $^{3}$ Thus, abrupt WAIS collapse is a major cause for concern. However, it is not known if or when such a collapse is likely to occur.

It should also be noted that sea level rise can also be caused by thermal expansion. As ocean waters warm, they expand, causing a rise in sea level. Over the next 100 years, barring the possibility for rapid collapse of the WAIS, thermal expansion is thought to represent the most significant contribution to sea level rise, though a significant portion of projected sea level rise would be from ice melt (Church et al. 2001).

\section{El-Niño Southern Oscillation}

El-Niño Southern Oscillation (ENSO) is a large-scale coupled ocean-atmosphere "teleconnection" pattern occurring in the tropical Pacific Ocean. ENSO is closely related to changes in both the east-west Walker Circulation (which helps drive strong easterly trade winds at tropical latitudes) and the upwelling of cooler water along the South American Pacific coastline. When the Walker Circulation weakens, the trade wind speeds decrease, and upwelling of cooler water subsides. This causes a net warming of the ocean and atmosphere off the Peruvian coastline - the warm phase of ENSO, known as El Niño. In other years, the Walker Circulation is particularly strong, and there are enhanced trade winds and upwelling in the tropical Pacific - the cold phase of ENSO, known as La Niña.

ENSO is not a true oscillation in that it has no regular period or amplitude. However El Niño and La Niña represent two stable steady-states for regional climate in the South Pacific. The longterm prediction skill for ENSO phase and intensity is currently limited. This also manifests in long-term climate models, which can currently produce ENSO-like variability, but are not able to conclusively predict trends towards stronger or weaker El Niño or La Niña and suggest a larger variability in the ENSO cycle (Timmermann et al. 1999). Global Circulation Models are limited in that they are unable to successfully replicate ENSO conditions given their coarse spatial resolution. In addition, given a set of 15 atmospheric models, the models could not agree as to the predicted change in average state and variability of the ENSO cycle (Merryfield 2006).

The influence of ENSO is not only felt in the tropical Pacific region, but worldwide. For example, an El Niño event can bring enhanced rainfall to California, and can cause warmer temperatures in the Northeastern United States. Predicting the future tendencies of ENSO, therefore, is important in assessing climate change at the regional scale.

\section{Regional climate}

As mentioned above, global mean temperature is not necessarily a robust indicator of aggregate climate change. Atmosphere-ocean climate models under global warming scenarios predict nonuniform change in temperature distribution across the planet. For example, greater warming often occurs over land masses than oceans because less available water reduces the magnitude of evaporative cooling. Warming also tends to increase the spatial variability of precipitation, leading to a drying of the subtropics and an increase in tropical and mid-latitude rainfall

\footnotetext{
${ }^{3}$ Specifically, increased ice stream velocities have been noted in several areas of WAIS, including Larsen (Scambos et al. 2004) and the vicinities of Pine Island and Thwaites Glaciers (Rignot et al. 2002).
} 
(Solomon et al. 2007). This spatial variability in precipitation, coupled with the poleward expansion of the subtropical high pressure belt under global warming (Lu et al. 2007; Seidel et al. 2008), points toward an intense reduction in precipitation at subtropical dry zones. Thus, climate change involves important regional changes in addition to increases in global mean temperature.

The current understanding of how climates will change in specific regions remains uncertain. Uncertainty in regional climate projection owes partially to the limitations of climate models. The resolution of global atmosphere-ocean models ranges from 400 to $125 \mathrm{~km}$, which makes finer scale variability difficult to resolve. However, these models can provide boundary conditions for nested regional climate models, which are capable of resolving detail down to 50 $\mathrm{km}$ - and some as small as $15 \mathrm{~km}$ (Solomon et al. 2007). Advances in computing will lead to increased resolution for both types of models. Nevertheless, improved prediction of regional responses to global warming will also require a better understanding of the underlying physics, including changes in cloud cover, radiative forcing, soil parameterization, and biomass feedback. In short, many of the challenges involved in regional climate forecasts are common to the pursuit of global climate projections.

\section{Climate Ethics}

What society should do about climate change is fundamentally an ethical question; the answer will depend (often heavily) on the choice of ethical framework. Because climate change affects humans and non-humans worldwide over very long time periods, it is an ethical issue of great importance. For this reason, there has been much discussion of what ethics should be used to address climate change and the implications of these choices. This discussion has been conducted by researchers from many disciplines including philosophy, economics, and geography. ${ }^{4}$

\section{Climate Ethics Overview}

A wide range of ethical analyses of climate change have already been conducted. Helpful introductions are provided by Broome (1992), Gardiner (2004), Brown et al. (2004), and Klinsky and Dowlatabadi (2009). Broome's, Gardiner's, and Brown and colleagues' works are intended primarily for economists, ethicists, and policy makers, respectively; Klinsky and Dowlatabadi's is intended for ethics and policy communities. However, each of these is relevant and accessible to wider audiences. Coward and Hurka (1993) also discuss a wide range of ethical perspectives, including both the religious and the secular, though some of the content is somewhat outdated.

Many of the analyses, particularly those conducted by economists, have used variations of anthropocentric utilitarianism. Other frameworks presented in the literature include those based on rights (Adger 2004; Caney 2008) and virtue (Jamieson 1992). Some major issues include how much emissions reductions to aim for (Baum 2007; Tol 2008), how to distribute permissions to emit (Neumayer 2000), how to handle uncertainty about the climate-society system (Brown

\footnotetext{
${ }^{4}$ Stephen Gardiner (2004) argues that climate change has received little attention from moral philosophers. Regardless of what one considers to be a little or a lot of attention, it is the case that climate change has seen at least some attention from moral philosophers. Meanwhile, non-philosophers studying climate ethics also draw on the work of moral philosophers.
} 
2003), and how to help humans and ecosystems adapt to what climatic changes will inevitably occur (Adger et al. 2006; UNDP 2007). Collectively, this research makes a clear and compelling case that climate change poses many major ethical issues. Initial research has shed some light on these issues, but much work remains undone.

\section{Climate Economics}

Economists often frame climate change as a market failure, meaning that markets fail to account for the costs and benefits of climate change in the prices of the greenhouse gas emissions that are responsible. The Stern Review calls climate change "the greatest and widest-ranging market failure ever seen" (Stern 2007, p.i). ${ }^{5}$ In response to this "market failure", economists typically recommend some sort of "market-based" climate policy, usually in the form of a global carbon tax or cap-and-trade system, with the tax usually being the preferred option. [See William Nordhaus (2007) for a common argument in favor of a carbon tax.] Climate economics research thus focuses on the rate of taxation by building in more detail about the climate system (e.g. McInerney and Keller 2007), about society (Howarth 2006), or by considering alternative ethical frameworks (see Baum 2007).

Climate economics research is dominated by a line of integrated climate-society modeling based on a particular "optimal growth" model known as the Ramsey model. This line of modeling has its origins in the work of Nordhaus (1992); Tol (2008) provides a recent review of the literature. There has been extensive ethical debate on how to choose parameter values for the model (Arrow et al. 1996; Baum 2007). In addition, the model has also been heavily criticized for its accuracy (c.f. Baum 2007; Gundermann 2002; Stern 2008) as well as for its sweeping assumption that there exists a universal decision maker for the entire planet (c.f. Morgan et al. 1999; Schelling 2000).

Some recent economic analyses of climate change have focused on the possibility that climate change could be catastrophic, meaning that it could have very large negative outcomes (Tol and Yohe 2007; Weitzman 2009). The analyses find that the possibility of catastrophe may be a very important factor even if the catastrophe is quite unlikely. This finding parallels general analyses of catastrophic risk (e.g. Bostrom 2003; Bostrom and Ćirković 2008; Matheny 2007; Posner 2004). The basic idea is that under ethical frameworks that place intrinsic value on human life and welfare, risks of ending human civilization or even causing human extinction should be avoided, perhaps even at all costs. ${ }^{6}$ Thus, the possibility that climate change could be catastrophic suggests, under these frameworks, that much effort should be made to reduce greenhouse gas emissions.

There are several scenarios in which climate change could be catastrophic, causing major and possibly irreversible harm to human civilization. One scenario involves a combination of high climate sensitivity and high emissions levels, leading to large amounts of climate change (Weitzman 2009). There is a chance that this scenario can be avoided via geoengineering.

\footnotetext{
${ }^{5}$ The Stern Review is a report on climate change commissioned by the UK government and lead by economist Nicolas Stern. The Review was heavily criticized by many economists, in large part for supporting a different ethical view than that of the critics (Baum 2007).

${ }^{6}$ Bruce Tonn (2002) demonstrates that ecocentric frameworks will often also place high priority in avoiding human extinction given the crucial role humanity may play in the very long-term survival of Earth-originating life.
} 
However, geoengineering does not offset all climate impacts and could itself lead to a catastrophic scenario in the event that it was abruptly ceased or used as a weapon (Robock 2008). Another catastrophic scenario, possible under even more moderate climate change, involves climate change contributing to a major global war. Already, some analysts expect climate change to exacerbate violent conflict due to such stressors as resource scarcity and migration (Sullivan et al. 2007); it is difficult to place an upper bound on how catastrophic such conflict could get. Thus, for those ethical frameworks that value future lives or welfare (human or otherwise), avoiding climate change should be a major priority.

Spier's Claims

In his editorial, Spier (2008) makes specific claims that are worth considering in greater detail.

1. An "increase in global temperature has beneficial effects as well as detrimental ones" (Spier $2008, p .2)$. This claim is certainly true, and importantly so. While climate change is primarily caused by the world's rich, the detrimental effects fall predominantly on the world's poor, causing a major case of distributive injustice, or, in legal terms, a tort (Sunstein and Rowell 2007). Furthermore, unlike the rich, the poor typically are less able to adapt to climate change, leading to a situation that Desmond Tutu calls "adaptation apartheid" (UNDP 2007, p.166). Meanwhile, groups that stand to benefit, such as the energy companies whose products drive climate change, may (and often do) hinder efforts to reach a strong global climate policy (Demeritt 2001; McKie and Galloway 2007).

2. "[S]pending money on attempts to limit or lessen the amount of $\mathrm{CO}_{2}$ in the atmosphere are not cost effective in achieving human benefits when the money could be spent otherwise" (Spier 2008, p.2). The accuracy of this claim depends on the extent to which benefits to future humans are included. Ethicists frequently argue that all humans should be valued equally, regardless of when they live (c.f. Broome 1992). Under this view, efforts to prevent catastrophes, including catastrophic climate change, are generally the most cost-effective; ongoing research aims to estimate the most cost-effective means of reducing catastrophic risk (Bostrom and Ćirković 2008). This claim of Spier's is based on an analysis (Lomborg 2007) which does not consider catastrophic risk and is thus ill-founded.

3. "[T]he global community should let the $\mathrm{CO}_{2}$ rise as it may and spend the money that the populace seems to want to devote to its stabilization or reduction on research" (Spier 2008, p.2) for energy that does not use fossil fuels. This recommendation is based on a cost-benefit analysis (i.e. Lomborg 2007) that is ethically and scientifically indefensible. ${ }^{7}$ Failure to reduce $\mathrm{CO}_{2}$ emissions will almost certainly cause major undeserved harms and may cause civilizational catastrophe. Financial support for energy research does not compensate for the death and destruction that would meanwhile occur. Furthermore, in our view, it is unethical to gamble the fate of humanity on technology that may never materialize. The most urgent research need related to climate change concerns its possible catastrophic outcome. This research includes the possible climatic impacts of geoengineering and the corresponding social dynamics and possible interactions between climate change and global warfare.

\footnotetext{
${ }^{7}$ Detailed critiques of Lomborg (2007) can be found in Ackerman (2008), Dasgupta (2007), and McKibben (2007).
} See also Danish Ecological Council (2002) for an extensive critique of Lomborg (2001). 


\section{Conclusion}

Climate change is a complex and important issue. The study of climate change spans many academic disciplines across the natural and social sciences, humanities, and engineering. Existing research finds that there is very strong evidence that the climate is changing, that these changes are driven primarily by human activity, and that the changes will have very large impact on natural and social systems. While there remains much uncertainty about climate change, this uncertainty does not alter these fundamental findings.

Climate change poses many major ethical issues. One issue is distributive justice, both for people at different locations around the world and for people at different points in time. Another issue is the responsibility of humanity to the environment, in particular whether this responsibility extends beyond the environment's ability to benefit humanity. Another issue is how to define and aggregate costs and benefits, which can determine how much effort should be expended to avoid climate change.

Because climate change is such a complex and interdisciplinary issue, and perhaps also because ethicists have not extensively studied climate change, sound ethical analysis of climate change is quite difficult. These difficulties are apparent in the recent editorial by Spier (2008) (and also in the book Cool It (Lomborg 2007) upon which the editorial is partially based) and we hope that this paper helps clarify some of the issues in the spirit of ongoing analysis. However, in our view, action on climate change should not wait until analysis has been completed; we recommend strong immediate action to both reduce greenhouse gas emissions and to help people adapt to the climatic changes that will inevitably occur.

\section{Appendix: A Simple Climate Model}

Climate science includes the use of mathematical and computational models in order to simulate the global climate system. These models are used to conduct computer-based experiments to explore the behavior of climate under different circumstances without needing to actually alter the physical atmosphere of Earth. The behavior of these models provides much insight about climate change and can also be used to rebut many points of climate skepticism. The following text describes a simple algebraic climate model that is based on the conservation of energy entering and leaving Earth. This model illustrates that greenhouse gases are necessary to warm the surface and thus rebuts a simple point of skepticism that would claim greenhouse gases are irrelevant to climate. Many more sophisticated points of skepticism can be rebutted with more sophisticated but qualitatively similar models, which means that this model is an effective starting point for understanding climate science.

To construct this model, we first consider only energy emitted from the sun and ignore atmospheric greenhouse gases. If we let $R_{E}$ be the radius of Earth, then $\pi R_{E}^{2}$ is the cross-sectional area of Earth and $4 \pi R_{E}^{2}$ is the area of Earth's surface. We let $S_{0}$ be the amount of solar energy reaching Earth per unit area and per unit time (technically known as the energy flux). We also let $\alpha$ be the fraction of incoming sunlight that gets reflected back to space, which means that $(1-\alpha)$ is the fraction absorbed at the surface. The total amount of energy absorbed at the surface of 
Earth per unit time can therefore be written as $S_{0}(1-\alpha) \pi R_{E}^{2}$. The surface of Earth also emits energy in the form of blackbody radiation that can be described in terms of energy per unit area per unit time as $\sigma T_{E}{ }^{4}$, where $\sigma=5.67 \times 10^{-8} \mathrm{~J} \mathrm{~s}^{-1} \mathrm{~m}^{-2} \mathrm{~K}^{-4}$ is the Stefan-Boltzmann constant and $T_{E}$ is Earth's surface temperature. This allows us to write $4 \pi R_{E}^{2} \sigma T_{E}{ }^{4}$ as the amount of energy per unit time emitted by the surface. In order to conserve total energy, the solar energy absorbed at the surface of Earth must equal the energy emitted by the surface. We can write this equation as

$$
S_{0}(1-\alpha) \pi R_{E}^{2}=4 \pi R_{E}^{2} \sigma T_{E}^{4}
$$

where we use $S_{0}=1370 \mathrm{~W} \mathrm{~m}^{-2}$ per day and $\alpha=0.30$ (i.e., $30 \%$ of incoming solar radiation is reflected back to space) as typical values for this period of Earth's history. Solving Eq. 1 for $T_{E}$ gives an equation for the surface temperature of Earth if the sun were the only energy source:

$$
T_{E}=\sqrt[4]{\frac{S_{0}(1-\alpha)}{4 \sigma}}
$$

We can evaluate Eq. 2 using the values described above to find that $T_{E}=255 \mathrm{~K}=-18.15^{\circ} \mathrm{C}$, which is below the freezing point of water. In other words, if the sun were the only source of energy (i.e., without greenhouse gases), the surface of Earth would be completely frozen and life as we know it could not exist.

Greenhouse gases are atmospheric particles that absorb some of the radiation coming from the surface and also emit energy downward to the ground and upward to space. We can extend our model to include greenhouse gases by representing the atmosphere as a layer above the surface that is transparent to sunlight but absorbs infrared radiation emitted by the surface. Let $\varepsilon$ be the fraction of energy coming from the surface that is absorbed by the atmosphere (technically known as the absorptivity of the atmosphere) so that the energy per unit time absorbed by the atmosphere is $4 \pi R_{E}^{2} \sigma T_{S}{ }^{4} \varepsilon$. Here we have replaced the surface temperature by $T_{S}$ to avoid confusion with $T_{E}$ in Eq. 2. The atmosphere itself radiates at a blackbody with energy flux of $\sigma T_{A}{ }^{4}$, where $T_{A}$ is the temperature of the atmosphere. $\varepsilon$ also represents the fraction of radiation that is emitted from an atmosphere (technically known as the emissivity of the atmosphere; the assumption that absorptivity equals emissivity is known as Kirchoff's law of thermal radiation). This allows us to write the amount of energy per unit time emitted by the atmosphere as $4 \pi R_{E}^{2} \sigma T_{A}{ }^{4} \varepsilon$ both downward toward the surface and upward toward space. This term uses the same $R_{E}$ as above because the radius of Earth and the radius of the atmosphere are nearly identical. In order to maintain conservation of energy, the energy absorbed by the atmosphere must equal the energy emitted by the atmosphere. In our model the atmosphere emits both upward and downward, i.e. in two directions, whereas the surface only emits in one direction. Therefore we can write this balance as

$$
4 \pi R_{E}^{2} \sigma T_{S}^{4} \varepsilon=2\left(4 \pi R_{E}^{2} \sigma T_{A}^{4} \varepsilon\right)
$$

Solving Eq. 3 for $T_{s}$ gives us: 


$$
T_{S}=2^{1 / 4} T_{A} .
$$

This gives us a relationship between surface temperature and atmospheric temperature for our model. We can now consider the total energy budget at the surface due to the absorption of sunlight and atmospheric greenhouse radiation:

$$
S_{0}(1-\alpha) \pi R_{E}^{2}+4 \pi R_{E}^{2} \sigma T_{A}^{4} \varepsilon=4 \pi R_{E}^{2} \sigma T_{S}^{4} .
$$

Here the two terms on the left hand side of Eq. 5 respectively represent the amount of solar and greenhouse energy absorbed at the surface, while the term on the right hand side represents the emission of radiation from the surface of Earth. We can rearrange and simplify Eq. 5 as

$$
S_{0}(1-\alpha)=4 \sigma\left(T_{S}^{4}-T_{A}{ }^{4} \varepsilon\right),
$$

so that we can substitute the relationship from Eq. 4 and then solve for the surface temperature $T_{S}$ to find

$$
T_{S}=\sqrt[4]{\frac{S_{0}(1-\alpha)}{2 \sigma(2-\varepsilon)}}
$$

This equation for surface temperature depends on the emissivity (or absorptivity) of the atmosphere $\varepsilon$, which contrasts with the radiative equilibrium balance in Eq. 2 that neglects absorption by the atmosphere. The global mean annual surface temperature of Earth today is $T_{S}=$ $288 \mathrm{~K}=14.85^{\circ} \mathrm{C}$; this value can be calculated from either multi-annual global data sets or more sophisticated climate models. These present-day Earth conditions are described by Eq. 7 with a value of $\varepsilon=0.77$ so that the magnitude of the greenhouse effect $\Delta T_{B}$ in this model is $\Delta T_{g}=T_{S}-T_{E}=33 \mathrm{~K}$. In other words, the atmospheric greenhouse effect of Earth provides an additional thirty degrees of warming to the surface and prevents global glaciation.

This model treats all greenhouse gases identically, such that $\varepsilon$ is proportional to the total amount of greenhouse absorbers. Under a global warming scenario, then, the model shows that surface warming should follow from an increase in atmospheric greenhouse gases because a greater value of $\varepsilon$ corresponds to an increase in atmospheric absorption and acts to raise surface temperature in Eq. 7. Thus we see that greenhouse effect can be understood through the balance of energy absorbed and emitted by the climate system.

\section{Acknowledgments}

William Easterling and Raymond Tutu provided helpful comments on previous drafts of this paper. Any remaining errors are our own.

\section{References}


Ackerman, F. (2008). Hot, it's not: Reflections on Cool It, by Bjorn Lomborg. Climatic Change, 89(3-4), 435-446.

Adger, W. N. (2004). The right to keep cold. Environment and Planning A, 36, 1711-1715.

Adger, N. W., Paavola, J., Huq, S., Mace, M. J. (Eds.) (2006). Fairness in adaptation to climate change. Cambridge, MA: MIT Press.

Alley, R. B. (2002). The two-mile time machine: Ice cores, abrupt climate change, and our future. Princeton, NJ: Princeton University Press.

Archer, D. (2005). The fate of fossil fuel CO2 in geologic time. Journal of Geophysical Research, doi:10.1029/2004JC002625

Arrhenius, S. (1896). On the influence of carbonic acid in the air upon the temperature of the ground. London, Edinburgh, and Dublin Philosophical Magazine and Journal of Science, 41(251), 237-276.

Arrow, K. J., Cline, W., Maler, K. G., Munasinghe, M., Squitieri, R., Stiglitz, J. (1996). Intertemporal equity, discounting and economic efficiency. In J. Bruce, H. Lee, E. Haites (Eds.), Climate Change 1995-Economic and Social Dimensions of Climate Change (pp. 125-144).

Cambridge, UK: Cambridge University Press.

Ascher, W. L. (2004). Scientific information and uncertainty: Challenges for the use of science in policymaking. Science and Engineering Ethics, 10(3), 437-455.

Baum, S. (2007). Beyond the Ramsey model for climate change assessments. Ethics in Science and Environmental Politics, 2007, 15-21.

Bostrom, N. (2003). Astronomical waste: The opportunity cost of delayed technological development. Utilitas, 15, 308-314.

Bostrom, N., Ćirković, M. (Eds.) (2008). Global catastrophic risks. Oxford: Oxford University Press.

Brohan, P., Kennedy, J. J., Harris, I., Tett, S. F. B., Jones P. D. (2006). Uncertainty estimates in regional and global observed temperature changes: A new dataset from 1850. Journal of Geophysical Research, 111, D12106, doi:10.1029/2005JD006548.

Broome, J. (1992). Counting the cost of global warming. Cambridge, UK: The White Horse Press.

Brown, D. A. (2003). The importance of expressly examining global warming policy issues through an ethical prism. Global Environmental Change, 13, 229-234.

Brown, D., Tuana, N., Averill, M., Baer, P., Born, R., Brandão, C. E. L., Frodeman, R., Hogenhuis, C., Heyd, T., Lemons, J., McKinstry, R., Lutes, M., Müller, B., Miguez, J. D. G., Munasinghe, M., de Araujo, M. S. M., Nobre, C., Ott, K., Paavola, J., de Cammppos, C. P., Rosa, L. P., Rosales, J., Rose, A., Wells, E., Westra, L. (2004). White paper on the ethical dimensions of climate change. http://rockethics.psu.edu/climate/whitepaper/whitepaperintro.shtml. Accessed 7 April 2011.

Caney, S. (2008). Human rights, climate change, and discounting. Environmental Politics, 17(4), 536-555.

Carslaw, K. S., Harrison, R. G., Kirkby, J. (2002). Cosmic rays, clouds, and climate. Science, 298(5599), 1732-1737.

Church J. A., Gregory, J. M., Huybrechts, P., Kuhn, M., Lambeck, K., Nhuan, Qin, D., Woodworth, P. L., Anisimov, O. A., Bryan, F. O., Cazenave, A., Dixon, K. W., Fitzharris, B. B., Flato, G. M., Ganopolski, A., Gornitz, V., Lowe, J. A., Noda, A., Oberhuber, J. M., O’Farrell, S. P., Ohmura, A., Oppenheimer, M., Peltier, W. R., Raper, S. C. B., Ritz, C., Russell, G. L., Schlosser, E., Shum, C. K., Stocker, T. F., Stouffer, R. J., van de Wal, R. S. W., Voss, R., Wiebe, 
E. C., Wild, M., Wingham, D. J., Zwally, H. J. (2001). Changes in sea level. In J. T. Houghton et al. (Eds.), Climate change 2001: The scientific basis (pp. 639-694). Cambridge, UK: Cambridge University Press.

Clark P.U., Alley R.B., and Pollard D. (1999) Northern Hemisphere Ice-Sheet Influences on Global Climate Change. Science, 286, 1104-1111.

Committee on Facilitating Interdisciplinary Research. (2004). Facilitating interdisciplinary research. Washington, DC: National Academies Press.

Conway H., Hall B.L., Denton G.H., Gades A.M., and Waddington E.D. (1999) Past and Future Grounding-Line Retreat of the West Antarctic Ice Sheet. Science, 286, 280-283.

Coward H., Hurka T. (1993). Ethics and climate change: The greenhouse effect. Waterloo, ON: Wilfrid Laurier University Press.

Crutzen, P. J. (2006). Albedo enhancement by stratospheric sulfur injections: a contribution to resolve a policy dilemma? Climatic Change, 77, 211-220.

Danish Ecological Council. (2002). Sceptical questions and sustainable answers. Copenhagen:

Danish Ecological Council.

Dasgupta, P. (2007). A challenge to Kyoto. Nature, 449, 143-144.

Demeritt, D. (2001). The construction of global warming and the politics of science. Annals of the Association of American Geographers, 9, 307-337.

Durkin, M. (2007). The great global warming swindle. Channel 4 (U.K.).

http://www.greatglobalwarmingswindle.co.uk. Accessed 7 April 2011.

Early J. T. (1989). Space-based solar shield to offset greenhouse effect. Journal of the British Interplanetary Society, 42, 567-569.

Gardiner, S. M. (2004). Ethics and global climate change. Ethics, 114, 555-600.

Gore, A. (2006). An inconvenient truth: The planetary emergency of global warming and what we can do about it. New York: Rodale Books.

Grenci, L. M., Nese, J. M. (2006). A world of weather: Fundamentals of meteorology. Dubuque, IA: Kendall/Hunt.

Gundermann, J. (2002). Discourse in the greenhouse. In Danish Ecological Council, Sceptical questions and sustainable answers (pp. 139-164). Copenhagen: Danish Ecological Council.

Hansen, J., Ruedy, R., Sato, M., Imhoff, M., Lawrence, W., Easterling, D., Peterson, T., Karl, T. (2001). A closer look at United States and global surface temperature change. Journal of Geophysical Research, 106, 23947-23963.

Harvey, L. D. D., Kaufmann, R. K. (2002). Simultaneously constraining climate sensitivity and aerosol radiative forcing. Journal of Climate, 15, 2837-2861.

Howarth, R. B. (2006). Optimal environmental taxes under relative consumption effects. Ecological Economics, 58, 209-219.

Jamieson, D. (1992). Ethics, public policy, and global warming. Science, Technology, \& Human Values, 17(2), 139-153.

Keith, D. W. (2000). Geoengineering the climate: History and prospect. Annual Review of Energy and the Environment, 25, 245-284.

Kerr, R. A. (2007). Pushing the scary side of global warming. Science, 316, 1412-1415.

King, J. C., Turner, J.; Marshall, G. J.; Connolley, W. M.; Lachlan-Cope, T. A. (2002). Antarctic Peninsula Climate Variability and its Causes as Revealed by Analysis of Instrumental Records. British Antarctic Survey, Natural Environment Research Council.

Klinsky, S., Dowlatabadi, H. (2009). Conceptualizations of justice in climate policy. Climate Policy, 9(1), 88-108. 
Knutti R., Hegerl, G. (2008). The equilibrium sensitivity of the Earth's temperature to radiation changes. Nature Geosciences, doi:10.1038/ngeo337

Kristjansson, J. E., Staple, A. Kristiansen J., Kaas E. (2002). A new look at possible connections between solar activity, clouds and climate. Geophysical Research Letters, 29, 2107-2110.

Kristjánsson, J. E., Kristiansen, J., Kaas, E. (2004). Solar activity, cosmic rays, clouds and climate-an update. Advances in Space Research, 34, 407-415.

Lawrence, R. J., Després, C. (2004). Futures of transdisciplinarity. Futures, 36, 397-405.

Leiserowitz A. (2006). Climate change risk perception and policy preferences: The role of affect, imagery, and values. Climatic Change, 77(1-2), 45-72.

Lomborg, B. (2001). The skeptical environmentalist: Measuring the real state of the world.

Cambridge, UK: Cambridge University Press.

Lomborg, B. (2007). Cool it: The skeptical environmentalist's guide to global warming. New York: Knopf.

Lu, J., Vecchi, G. A., Reichler, T. (2007). Expansion of the Hadley cell under global warming. Geophysical Research Letters, 34, L06805, doi:10.1029/2006GL028443.

Lugina, K. M., Groisman, P. Y., Vinnikov, K. Y., Koknaeva, V. V., Speranskaya, N. A. (2005).

Monthly surface air temperature time series area-averaged over the 30-degree latitudinal belts of the globe. Carbon Dioxide Information Analysis Center, Oak Ridge National Laboratory, US Department of Energy. http://cdiac.esd.ornl.gov/trends/temp/lugina/lugina.html. Accessed 7 April 2011.

Marsh, N., Svensmark, H. (2000a). Cosmic rays, clouds, and climate. Space Science Reviews, 94, 215-230.

Marsh, N. D., Svensmark, H. (2000b). Low cloud properties influenced by cosmic rays. Physical Review Letters, 85, 5004-5007.

Martin, J. H. (1990). Glacial-interglacial CO2 change: The iron hypothesis. Paleoceanography, 5, $1-13$.

Matheny, J. G. (2007). Reducing the risk of human extinction. Risk Analysis, 27(5), 1335-1344. McKibben, B. (2007). Can anyone stop it? New York Review of Books, 54(15), 11 October.

McKie, D., Galloway, C. (2007). Climate change after denial: Global reach, global responsibilities, and public relations. Public Relations Review 33, 368-376.

McInerney, D., Keller, K. (2007). Economically optimal risk reduction strategies in the face of uncertain climate thresholds. Climatic Change, doi:10.1007/s10584-006-9137-z

Merryfield, W. J., 2006: Changes to ENSO under CO2 Doubling in a Multimodel Ensemble. Journal of Climate, 19, 4009-4027

Morgan, M. G., Kandlikar, M., Risbey, J., Dowlatabadi, H. (1999). Why conventional tools for policy analysis are often inadequate for problems of global change. Climatic Change, 41, 271281.

Morton, O. (2007). Is this what it takes to save the world? Nature, 447, 132-136.

Moss, R. H., Schneider, S. H. (2000). Uncertainties in the IPCC TAR: Recommendations to lead authors for more consistent assessment and reporting. In R. Pachauri, T. Taniguchi, K. Tanaka (Eds.), Guidance papers on the cross cutting issues of the Third Assessment Report of the IPCC (pp. 33-51). Geneva: World Meteorological Organization.

Neumayer, E. (2000). In defence of historical accountability for greenhouse gas emissions.

Ecological Economics, 33, 185-192.

Nobel Foundation (2007). The Nobel Peace Prize 2007.

http://nobelprize.org/nobel_prizes/peace/laureates/2007. Accessed 15 October 2008. 
Nordhaus, W. (1992). An optimal transition path for controlling greenhouse gases. Science, 258(5086), 1315-1319.

Nordhaus, W.D. (2007). To tax or not to tax: Alternative approaches to slowing global warming. Review of Environmental Economics and Policy, 1(1), 26-44.

Nordhaus, W.D. (2008). A question of balance: Weighing the options on global warming policies. New Haven, CT: Yale University Press.

Overpeck J.T., Otto-Bliesner B.L., Miller G.H., Muhs D.R., Alley R.B., and Kiehl J.T. (2006)

Paleoclimatic Evidence for Future Ice-Sheet Instability and Rapid Sea-Level Rise. Science, 311, 1747-1750.

Petit, J. R., Jouzel, J., Raynaud, D., Barkov, N. I., Barnola, J. M., Basile, I., Bender, M., Chappellaz, J., Davis, M., Delaygue, G., Delmotte, M., Kotlyakov, V. M., Legrand, M., Lipenkov, V. Y., Lorius, C., Pépin, L., Ritz, C., Saltzman, E., Stievenard, M. (1999). Climate and atmospheric history of the past 420,000 years from the Vostok ice core, Antarctica. Nature, 399, 429-436.

Pittock, A. B. (2002). What we know and don't know about climate change: Reflections on the IPCC TAR. Climatic Change, 53(4), 393-411.

Pollard D., and DeConto R.M. (2009) Modelling West Antarctic ice sheet growth and collapse through the past five million years. Nature, 458, 329-332.

Posner, R. (2004). Catastrophe: Risk and response. Oxford: Oxford University Press.

Ramaswamy, V., Chanin, M. L., Angell, J., Barnett, J., Gaffen, D., Gelman, M., Keckhut, P., Koshelkov, Y., Labitzke, K., Lin, J.-J. R., O'Neill, A., Nash, J., Randel, W., Rood, R., Shine, K., Shiotani, M., Swinbank, R. (2001). Stratospheric temperature trends: Observations and model simulations. Reviews of Geophysics, 39, 71-122.

Ravetz, J. R. (1999). What is post-normal science. Futures, 31, 647-653.

Rignot, E., Vaughan, D. G., Schmeltz, M., Dupont, T., MacAyeal, D. (2002). Acceleration of

Pine Island and Thwaites glaciers. Annals of Glaciology, 34(1), 189-194.

Rignot E., and Kanagaratnam P. (2006) Changes in the Velocity Structure of the Greenland Ice Sheet. Science, 311, 986-990.

Robock, A. (2008). 20 reasons why geoengineering may be a bad idea. Bulletin of the Atomic Scientists, 64(2), 14-18, 59.

Saundry, P., Vranes, K. (2008). Intergovernmental Panel on Climate Change (IPCC). In: J.C. Cleveland (Ed.), Encyclopedia of Earth.

http://www.eoearth.org/article/Intergovernmental_Panel_on_Climate_Change_(IPCC). Accessed 7 April 2011.

Scambos, T. A; Bohlander, J. A.; Shuman, C. A.; and Skvarca, P. (2004). Glacier Acceleration and Thinning after Ice Shelf Collapse in the Larsen B Embayment, Antarctica. Geophysical Research Letters. 31, L18402.

Schelling, T. (2000). Intergenerational and international discounting. Risk Analysis, 20(6), 833837.

Schneider, S.H. (2001). A constructive deconstruction of deconstructionists: A response to Demeritt. Annals of the Association of American Geographers, 91(2), 338-344.

Schneider, S.H. (2006). Climate change: Do we know enough for policy action?. Science and Engineering Ethics, 12, 607-636.

Schneider, S.H. (2008). Geoengineering: could we or should we make it work?. Philosophical Transactions of the Royal Society A, 366(1882), 3843-3862. 
Seidel, D. J., Fu, Q., Randel, W. J., Reichler, T. S. J. (2008). Widening of the tropical belt in a changing climate. Nature Geoscience, 1, 21-24.

Seifritz, W. (1989). Mirrors to halt global warming?. Nature, 340, 603.

Shaw, A., Robinson, J. (2004). Relevant but not prescriptive? Science policy models within the IPCC. Philosophy Today, 48, 84-95.

Shepherd A., and Wingham D. (2007) Recent Sea-Level Contributions of the Antarctic and Greenland Ice Sheets. Science, 315, 1529-1532.

Smetacek, V., Naqvi, S. W. A. (2008). The next generation of iron fertilization experiments in the Southern Ocean. Philosophical Transactions of the Royal Society A, 366, 3947-3967. Smith, T. M., Reynolds, R. W. (2005). A global merged land-air-sea surface temperature reconstruction based on historical observations (1880-1997). Journal of Climate, 18, 2021-2036. Solomon, S., Qin, D., Manning, M., Chen, Z., Marquis, M., Averyt, K. B., et al. (Eds.) (2007). Climate Change 2007: The physical science basis. Contribution of Working Group I to the Fourth Assessment Report of the Intergovernmental Panel on Climate Change. Cambridge, UK: Cambridge University Press.

Spier R. E. (2008). Climate - an item for the ethics agenda. Science and Engineering Ethics, 14(1), 1-2.

Stern, D. I. (2005). Global sulfur emissions from 1850 to 2000. Chemosphere, 58, 163-175. Stern, N. (2007). The economics of climate change: The Stern review. Cambridge, UK: Cambridge University Press.

Stern, N. (2008). The economics of climate change. American Economic Review, 98, 2-37. Stott, P. A., Mitchell, J. F. B., Allen, M. R., Delworth, T. L., Gregory, J. M., Meeh1, G. A., Santer, B. D. (2006). Observational constraints on past attributable warming and predictions of future global warming. Journal of Climate, 19, 3055-3069.

Sullivan, G. R., Bowman, F., Farrell, L. P., Gaffney, P. G., Kern, P. J., Lopez, T. J., Pilling, D. L., Prueher, J. W., Truly, R. H., Wald, C. F., Zinni, A. C. (2007). National security and climate change. Alexandria, VA: The CNA Corporation.

Sun, B., Bradley, R. S. (2002). Solar influences on cosmic rays and cloud formation: A reassessment. Journal of Geophysical Research, 107, D14205, doi:10.1029/2003JD004063. Sunstein, C. R., Rowell, A. (2007). On discounting regulatory benefits: Risk, money, and intergenerational equity. University of Chicago Law Review, 74(1), 171-208.

Timmermann, A., Oberhuber, J., Bacher, A., Esch, M., Latif, M., Roeckner, E. (1999). Increased El Nino frequency in a climate model forced by future greenhouse warming. Nature, 398, 694697.

Tol, R. S. J. (2008). The social cost of carbon: Trends, outliers and catastrophes. Economics, 2, 2008-25.

Tol, R. S. J., Yohe, G.W. (2007). Infinite uncertainty, forgotten feedbacks, and cost-benefit analysis of climate policy. Climatic Change, 83, 429-442.

Tonn, B.E. (2002). Distant futures and the environment. Futures, 34, 117-132.

Turner, J, Colwell, S. R., Marshall, G. J., Lachlan-Cope, T. A., Carleton, A. M., Jones, P. D., Lagun, V., Reid, P. A. Iagovkina, S. (2005). Antarctic climate change during the last 50 years. International Journal of Climatology, 25, 279-294.

UNDP. (2007). Human Development Report 2007/2008: Fighting climate change: Human solidarity in a divided world. New York: United Nations Development Programme.

Washington Times. (2007). Global warming labeled a 'scam'. March 6. http://www.washtimes.com/news/2007/mar/06/20070306-122226-6282r. Accessed 7 April 2011. 
Weitzman, M. L. (2009). Structural uncertainty and the value of statistical life in the economics of catastrophic climate change. Review of Economics and Statistics, 91(1), 1-19.

Zwally, H. J., Abdalati, W., Herring, T., Larson, K., Saba, J., Steffen, K. (2002). Surface meltinduced acceleration of Greenland ice-sheet flow. Science, 297(5579), 218-222. 